УДК 78.08/.082/.083+786.2

\author{
Гань Сяосюе, \\ соискатель кафедры истории музыки \\ и музыкальной этнографии \\ ОНМА им. А. В. Неждановой \\ odma_n@ukr.net

\section{ПОНЯТИЕ ФОРМЫ И ПРОЦЕСС ФОРМООБРАЗОВАНИЯ В ФОРТЕПИАННОЙ МУЗЫКЕ: ХОЛИСТИЧЕСКИЙ ПОДХОД}

Цель статьи - раскрыть значение категории формы применительно $\kappa$ фортепианному творчеству, учитывая композиторский, исполнительский и музыковедческий подходы к нему. Методология работы включает исторический и теоретико-аналитический музыковедческие методы, принципы музыкально-исполнительской текстологии, базируется на холистическом подходе. Научная новизна исследования заключается $в$ создании целостной концепции природы и способов формообразования в фортепианной музыке, позволяющей определять общие параметры композиторского и исполнительского творчества. Выводы. Форма и формообразования выступают главными критериями родового, видового и композиционного своеобразия музыкального искусства, музыкальнотворческого процесса. Их отличительным качеством является единство композиторской и исполнительской, структурной и семантической сторон, антиципации и апперцепции, выражающее целостность музыкального образа и его воздействия.

Ключевые слова: форма, формообразование, холистический подход, фортепианная музыка, музыкально-творческий процесс, музыкальный образ, музыкальное воздействие.

Gan Xiaoxue, applicant of the Department of music history and musical ethnography, ONMA named after A. V. Nezhdanova.

Concept of the form and process of shaping of piano music: holistic approach

Article purpose - to disclose value of category of a form in relation to piano creativity, considering composer, performing and musicological approaches to him. The methodology of work includes historical and theoretical and analytical musicological methods, the principles of musical-performing textology, is based on holistic approach. The scientific novelty of a research consists in creation of the complete concept of the nature and ways of shaping in the piano music allowing to determine the general parameters of composer and performing creativity. Conclusions. The form and shapings act as the main criteria of a patrimonial, specific and composite originality of musical art, musical and creative process. Their distinctive quality is the unity of the composer and performing, structural

(C) Гань Сяосюе, 2016 
and semantic parties, antitsipation and appertseption expressing integrity of a musical image and its influence.

Keywords: form, shaping, holistic approach, piano music, musical-creative process, musical image, musical influence.

Гань Сяосюе, здобувач кафедри історії музики та музичної етнографіі ОНМА ім. А. В. Нежданової

Поняття форми і процесу формоутворення у фортепіанній музиці: холістичний підхід

Мета статті - розкрити значення категорії форми стосовно фортепіанної творчості, враховуючи композиторський, виконавський $і$ музикознавчий підходи до неї. Методологія роботи включає історичний $i$ теоретико-аналітичний музикознавчі методи, принципи музично-виконавської текстології, базується на холістичному підході. Наукова новизна дослідження полягає у створенні цілісної концепиії природи і способів формоутворення у фортепіанній музиці, що дозволяє визначати загальні параметри композиторської та виконавської творчості. Висновки. Форма і формоутворення виступають головними критеріями родової, видової і композиційної своєрідності музичного мистецтва, музично-творчого процесу. Їх відмітною якістю є єдність композиторської та виконавської, структурної та семантичної сторін, антиципації та апперцепції, що виражає цілісність музичного образу та його діяння.

Ключові слова: форма, формоутворення, холістичний підхід, фортепіанна музика, музично-творчий процес, музичний образ, музичний вплив.

Актуальность темы и круга проблемных вопросов данного исследования обусловлена необходимостью развития аналитического подхода, предложенного В. Холоповой и позволяющего трактовать сушественно шире само понятие «анализ». Данный подход связан с обрашением не только к конкретным композиционным решениям отдельных произведений, но к природе формообразования в музыке в целом, а следовательно, к эстетическим и семантическим параметрам музыки как особой художественной форме (в отличие от живописи, литературы, архитектуры и так далее).

В. Холопова отмечает: «Семантичны и сами музыкальные композиции - их типы, разновидности, индивидуальные случаи. Музыкальные формы запечатлевают в себе характер музыкального мышления, причем, мышления многослойного, отражающего идеи эпохи, национальной художественной школы, стиль композитора и так далее. Таким образом, и объект рассмотрения - формы, композиции музыкальных произведений, - и методы анализа должны быть связаны с выразительно-смысловой сферой музыки» $[9,53]$. 
Категорию «музыкальная форма» Холопова связывает с содержательной, выразительно-смысловой, интонационной сущностью музыкального произведения. В связи с этим музыкальную форму можно рассматривать как универсальный фактор развития музыки как вида художественного творчества. Холопова предлагает рассматривать данное явление на трех уровнях.

Первый из них определяется содержанием музыкальной формы как феномена, по сути - эстетическим назначением музыки, как ее «специальным стилем»: «...это идеальный мир прекрасного, несущий в себе этическую идею добра к человеку, эстетическую идею гармонии мироздания и психологически - эмоцию радости... Соответственно и наука о музыкальной форме - это наука о музыкально-прекрасном, об идеальном, «специальном» слое содержания музыки» $[9,72]$.

Второй уровень функционирования музыкальной формы связан с исторической типизацией композиции, которая осуществляется как становление жанра - в том числе и жанровой семантики. Данный уровень является по отношению к первому конкретизирующим и обособляющим, - но в пределах общих жанровых форм. Именно для данного уровня особенно важным, на наш взгляд, становится взаимодействие музыки с внемузыкальными художественными элементами; в основе любого жанра лежит определенная программа эстетическая идея, композиционная логика, близкая к сюжетной, способ образного сопоставления (контраст или его отсутствие) и так далее. Смысловая определенность, явность, доступность данной программы возникает благодаря длительному сосуществованию музыки и словесных, зрелищных видов искусства (достаточно вспомнить исследование В. Конен «Театр и симфония», раскрывающее буквальную преемственность «чистой» симфонии по отношению к опере). Программность в музыке раскрывает свое главное назначение именно в связи с историческими типами жанров, способствуя сохранению прежней жанровой семантики и движению к новой. Данное движение происходит как стилевое обновление жанра, подчеркивающее сложно-динамическую природу последнего.

Хотя В. Холопова не упоминает в данном случае о взаимодействии жанра и стиля, в других работах она обнаруживает в явлении стиля ту же иерархию, что и в феномене музыкальной формы. Поэтому рассмотрение музыкальной формы как индивидуальной композиции произведения по ее концепции, непосредственно связано с изучением индивидуально-авторского стиля, а последний в музыке 
предполагает подключение и исполнительской стороны. Нетипизированность, оригинальность трактовки музыкальной формы в творчестве того или иного композитора могут быть обнаружены только на фоне устойчивых жанровых принципов музыки как языка, а оригинальность исполнительского плана выражения открывается в контексте устойчивых черт стиля композитора, следовательно, взаимодействие жанрового и стилевого уровней является важным контекстом изучения принципов музыкального формообразования, допускают использование понятий жанровой и стилевой формы в их сопоставлении с категорией композиции как единичного временного развертывания музыкального произведения. В. Холопова пишет следующее: «Из трех содержательных уровней музыкальной формы первый, метауровень, универсален и присутствует во всех музыкальных произведениях. Второй, близкий категории жанра в семиотическом смысле, наиболее четкий семантически, - исторически локален. Третий уровень - непременен, но градации его колеблются от минимального отклонения от стандарта типовой формы до неповторимой, уникальной музыкальной композиции» $[9,75]$.

Цель статьи - раскрыть значение категории формы применительно к фортепианному творчеству, учитывая композиторский, исполнительский и музыковедческий подходы к нему.

Основное содержание работы. Художественная форма изначально обусловлена образными содержательными заданиями, которые в музыке связаны со специфической программностью, если трактовать данное понятие в широком эстетическом значении. Подтверждением той мысли, что формирование жанров обусловлено развитием программного начала в музыке, является характеристика эстетики, литературно-поэтических прототипов, композиционно-драматургических принципов в музыке романтизма. Так, В. Холопова предполагает, что главные достижения романтической музыки связаны с вхождением через программность в образный мир поэзии, овладение ее смысловой логикой; по словам Холоповой, вместе с литературно-поэтическими ориентациями музыка усваивает иное отношение к категории времени: вместо классической замкнутости и стабильности тяготеет к разомкнутости и изменяемости; усваивает новое философское отношение Добра и Зла: наряду с надеждой на божественную справедливость и Добро, видит присутствие в мире сатанинского начала и Зла.

Новые жанры романтической музыки отличались намеренным смешением композиционных принципов различных классических 
форм; результатом данного смешения можно считать возникновение смешанных и полностью индивидуальных форм. Новизна романтического формообразования сказывается также в использовании временной последовательности музыкального звучания, то есть в способах процессуального развертывания музыкальной композиции. К сказанному следует добавить, что окончательной жанровой и стилевой автономией, а также признанием самостоятельности своей исполнительской стороны, соответственно исполнительской формы музыкального творчества, музыкальное искусство обладает, начиная с романтического периода. И именно в эпоху романтизма формируется пианистическая школа, то есть устанавливаются особые стилевые критерии фортепианно-исполнительского творчества. Учитывая тот факт, что временная природа музыки открывается и проявляется во всех своих композиционных и драматургических закономерностях именно в исполнительском процессе, осуществляется как «хроноартикуляционное» (термин М. Аркадьева) развертывание звучания, в становлении основных форм фортепианной музыки, тех, которые представляют органическое единство жанрового и стилевого факторов, условий музыкально-содержательной организации, исполнительская сторона, опыт исполнительского творчества оказываются если и не ведущими, то несомненно опорными, позволяющими проверять все аспекты художественного воздействия музыкального звучания. Среди них на первое место выходит цикл и цикличность - как фундаментальное свойство формообразования, приобретающее в музыке (в частности, в фортепианной) широкое структурно-семантическое проявление, возникающее в барочноклассицистский период, но достигающее художественного разнообразия, завершенности и функциональной независимости в творчестве романтиков.

В принципе, все названные Холоповой типы романтических музыкальных форм обладают качеством цикличности. От классической цикличности романтическое формообразование отличается программно-содержательной установкой, оправданностью цикла. Способ построения цикла указывает на эстетическую доминанту произведения. Важно отметить, что данные наблюдения касаются не только инструментальной, но и театральной, оперной музыки романтизма, что указывает на универсальность принципа цикличности для музыкального творчества, музыкального мышления. Особое внимание привлекает выделение Холоповой двух разновидностей сонатной 
формы - сонатно-циклической и сонатно-сюитной; дополнением к последней может служить контрастно-составная форма.

Как одно из самых ярких открытий в музыке романтизма, контрастно-составная форма влияет на принципы формообразования во всех жанрах. В связи с этим очень интересно предложенное Холоповой определение данной формы: контрастно-составной называется форма, состоящая из двух или нескольких частей, обладающая контрастом циклического типа (темповым, тематическим, ладотональным), самостоятельностью формы одной или более частей, непрерывностью звучания, мотивно-тематическими связями частей. Важно подчеркнуть, что контрастно-составная форма может реализовываться и в одночастной композиции. Именно отсюда такие ее определения, как слитно-циклическая, слитно-сюитная, слитный цикл и слитная сюита, введенные В. Цуккерманом и Л. Мазелем [2; 3]; можем добавить к этому определение М. Канчели - цикл, сжатый в одночастность [1]. В романтической музыке контрастно-составной форме - цикличности сопутствует поэмность, а последняя, как известно, так или иначе позволяет увидеть, как взаимодействуют все жанровые и индивидуально-композиционные уровни формы.

Предлагая программно ориентированный подход, В. Холопова, однако, последовательно его не проводит. Можно предположить, что в силу этого она не выделяет особые, присущие именно романтическому методу, способы жанрово-стилевого диалога, которые будут оказывать существенное влияние на композиторскую и исполнительскую традицию в начале XX века. Иначе говоря, остаются незамеченными предпосылки и истоки неоромантизма, который весомо утверждается в европейской музыке начала $\mathrm{XX}$ века именно в области формообразования и содержательной трактовки формы. Весьма бегло освещается вопрос о сонатно-сюитной форме, связанной с танцевальными и песенными жанрами. Между тем сближение сонаты и сюиты можно считать одним из парадоксов романтической музыки, поскольку соната и сюита представляют собой принципиально различные по природе циклы, что справедливо утверждается в исследовании В. Бобровского. Чем объясняется этот парадокс и какое значение приобретает в сближении различных типов цикла танцевальная семантика? Холопова приводит пример смешения сюиты из двух танцев - тарантеллы и неаполитанской канцоны - с сонатной формой (также и с вариациями второй темы) - Тарантелла «Венеция - Неаполь» g-moll из «Годов странствий» Листа. Здесь главная партия - 
минорная тарантелла, побочная партия в экспозиции - неаполитанская канцона, которая в репризе путем жанровой трансформации становится мажорной тарантеллой, синтезируя жанр главной партии с темой и ладом побочной партии.

Особенностью формообразования в музыке первой половины XX века, как справедливо отмечает В. Холопова, является то, что основные типы форм, на которые ориентировались композиторы, остались прежние (классические, барочные, романтические), но модернизировались организующие их элементы музыкального языка - тематизм, гармония, ритмика, мелодия, фактура. Изменились и соотношения этих элементов в организации музыкальной формы. Однако следует отметить, что хотя формы сохраняют свои прежние типы, но благодаря модернизации и новой расстановке формообразующих основ они качественно обновляются, удерживая стабильно лишь свою архитектонику. Так, например, в первой половине XX века инструментальные циклы приобрели ряд новых свойств. Появились циклы многочастные (симфонические), они стали репризными. Это выразилось и в напоминании в финале каких-либо тем из первой и других частей, а также во введении обособленных разделов - реприз цикла. В сонатной же форме одной из тенденций времени является преодоление репризности. Заметим, что Е. Назайкинский в условиях репризности выделяет необходимость некоторого временного расстояния, удаление от первоначального изложения материала. По его мнению, для эффекта репризности необходимо повторение мысли, а не только словесной или интонационной конструкции (собственно реприза возникает тогда, когда складывается впечатление повторения определенной мысли в иных условиях, в ином контексте, а не повторения слов или интонаций, включенных в выражение различных мыслей). Также реприза естественно возникает при ослаблении или полном снятии метрического корреспондирования ее с первоначальным проведением тематического материала (в инструментальной музыке такое корреспондирование в сочетании с мотивно-тематическими повторениями дает эффект синтаксических связей и синтаксических смыслов; оно как бы компенсирует отсутствие смысловых отношений, обеспечиваемых в пении предметными, конкретными значениями слов). Наконец, репризности способствует контрастный характер частей, разделяющих экспозицию и репризу (именно контрастность, нарушая ощущение единства музыкального развития, требует своего же отрицания в репризе) [4]. 
Реприза, репризность (в отличие от буквального повторения) есть повтор мысли в другой музыкально-смысловой ситуации; цикличность же раскрывается как создание ряда новых смысловых ситуаций в условиях единой «круговой», повторяющейся и продленной музыкальной композиции. Следовательно, цикличность и репризность являются различными, но тесно взаимосвязанными полюсами музыкальной повторности. А сама повторность - основа всего процесса формообразования в музыке и всех его структурных обособлений

Особое внимание Е. Назайкинский уделяет эстетико-художественным требованиям формы (жанровой и стилевой) миниатюры, поскольку двойная природа времени в миниатюре приводит к эффекту особой напряженности, насыщенности, концентрированности музыкального материала и принципов его развития. Они опираются на исторически сложившиеся закономерности синтаксических («масштабно-тематических») структур музыкальной речи, на явления метров высшего порядка, и одновременно вовлекают в действие функциональные свойства композиционных разделов и их жанровые проявления, а также закономерности квазисюжетного построения [4].

Как уже отмечалось, в круг теоретических вопросов о принципах функционирования музыкальной формы и особенностях ее структуры неизбежно входят вопросы о жанрообразовании и стилевом развитии музыки.

Не случайно и обособление формы миниатюры, и устойчивые попытки ее продления - расширения в масштабе циклической композиции (как в циклах фортепианных прелюдий или этюдов, программных пьес), и осмысление метода циклической композиции как сюжетно и событийно важного для музыкального творчества принадлежат к романтическому стилевому времени музыкальной истории. Так, последовательно, обнаруживается тесная связь принципов циклической формы с процессами стилеобразования, а само явление стиля также может быть охарактеризовано с циклической стороны, чему способствует включение исторического подхода к феномену музыкального формообразования на его различных, прежде всего, жанрово-стилевых, уровнях.

Так, С. Тышко определяет основные функции и динамические факторы стиля, его главные конструктивные направляющие, и выводит следующее определение: «Стиль в музыке - это система устойчивых признаков музыкальных явлений, способ их дифференциации и интеграции на различных уровнях (авторская индивидуальность, 
направление и школа, историческая эпоха, национальная специфика и тому подобное), переход их смысловых полей в конкретные системы музыкально-выразительных средств» [5, 5]. Автор выделяет две основные функции национального стиля в музыке: стилевая адаптация - поиск точек соприкосновения между «своим» и «чужим» материалом, движение к их стилевому компромиссу; стилевая генерация, то есть создание новых стилевых признаков на основе собственного национального материала, в условиях его известной оппозиции к вненациональному.

Автор отмечает, что динамические компоненты национального стиля являются полной противоположностью стилизации, так как последняя всегда «вторична» по отношению к стилевому прообразу и всегда осознается как стилевое явление. Динамические компоненты, в свою очередь, как бы содержат новый стиль в потенциале, предшествуют ему и, как правило, воспринимаются композиторами и слушателями не как признаки стилевого порядка, а как явления художественно-концептуальные, образные и так далее. И лишь в исторической перспективе обозначаются как изначальные точки новых стилевых движений. Таким образом, открытие каждой эпохой новых динамических компонентов стиля в произведении - свидетельство его изменяемости во времени, залог его «вечной актуальности» [5, 10], а процесс национального стилеобразования цикличен. Первый из хронологических циклов обязательно включает в строго определенной последовательности три стадии: изоляцию, экспансию и синтез. Они, в свою очередь, выражают типы контактов «своих» и «чужих» стилевых компонентов и организуют процессы ассимиляции (в последующих циклах порядок смены стадий более свободен, и они функционируют как тенденции стилеобразования).

Первая стадия - изоляция. Национальный музыкальный материал, впервые введенный в инородную жанрово-стилевую целостность, окружен стилевым «кордоном», его связи с художественным контекстом ограничены по всем параметрам - от музыкально-языкового до образно-драматургического. С позиции теории преемственности эта стадия может быть охарактеризована как диффузия стилевых элементов.

Вторая стадия - экспансия: новый национально-стилевой элемент завоевывает целые музыкальные произведения, например, фортепианной музыки или оперного творчества, полностью подчиняя себе их стилевой облик и являясь стимулом к жанровому эксперименту. 
Третья стадия - синтез, когда новый устойчивый стилевой признак, прошедший достаточно длительный путь стилевой адаптации, органично вписывается в художественный контекст, создавая иллюзию «гладкости», естественности национального стилеобразования.

Проблема связи «своего» и «чужого» в контексте формальных признаков одного произведения снимается, но мигрирует на макроуровень - в область связи произведения с общестилевым контекстом эпохи. На этом уровне стилевой барьер, характерный для стадии изоляции, не только остаётся, но ощущается еще сильнее, благодаря раскрепощению национально-стилевой энергии и переключению внимания с задач адаптации на функцию стилевой генерации (последняя на стадии экспансии всегда является ведущей) [5, 11-12].

Последовательность стадий национального стилеобразования была выработана и переформирована самим музыкально-историческим процессом, который характеризуется постоянным усложнением и разветвлением жанрово-стилевых систем, ускорением их развития, что приводит к синхронному «наложению» различных стадий, причем это становится возможным в пределах одного произведения, то есть в форме единичной композиции, которая усиливает, таким образом, свою внутреннюю цикличность, иногда формально-потенциальную, а стилевые отношения переводит на уровень смысловой полифонии. Подчеркнем также, что стремление к определенности и своеобразию процесса формообразования, наряду с совершенствованием формальных факторов музыкального творчества, обусловлено самой природой явления формы, которая этимологически указывает на выражение прекрасного как проступание внешних очертаний внутреннего образного содержания, связанного с эстетически совершенной интенцией (напомним, что слово «форма» происходит от латинского «вид, образ, красота» и древнегреческого «вид, очертания, внешность, красота»).

Выводы. Форма и формообразования выступают главными критериями родового, видового и композиционного своеобразия музыкального искусства, музыкально-творческого процесса. Их отличительным качеством является единство композиторской и исполнительской, структурной и семантической сторон, антиципации и апперцепции, выражающее целостность музыкального образа и его воздействия.

На наш взгляд, в европейской фортепианной музыке эпохи романтизма ярко проявляется совмещение тенденций стилевой адапта- 
ции и стилевой генерации - как продолжение исторического опыта музыкального формообразования и углубление феномена «стилевой памяти» музыки. Именно связь с историческим стилевым опытом европейского искусства обусловливает отношение композитора и исполнителя к смысловым задачам фортепианного творчества и возможностям понимания семантических установок формы, процесса формообразования в музыке.

\section{СПИСОК ЛИТЕРАТУРЫ}

1. Канчели М. Крупная одночастная форма в музыке XIX и на рубеже XX веков // Вопросы теории музыки. М.: Музыка, 1970. Вып. 2. С. 153-173.

2. Мазель Л. Строение музыкальных произведений. М.: Музыка, 1979. $534 \mathrm{c}$.

3. Мазель Л., Цуккерман В. Анализ музыкальных произведений. Элементы музыки и методика анализа малых форм. М.: Музыка, 1967. 752 с.

4. Назайкинский Е. Логика музыкальной композиции. М.: Музыка, 1982. $319 \mathrm{c}$.

5. Тышко С. Проблема национального стиля в русской опере. Глинка, Мусоргский, Римский-Корсаков. К.: Киевская государственная консерватория имени П. Чайковского, 1993. 117 с.

6. Холопова В. Музыка как вид искусства. М.: Научно-творческий центр «Консерватория», 1990. 260 с.

7. Холопова В. Музыкальный тематизм: [Научно-методический очерк. M.,1983. $88 \mathrm{c}$.

8. Холопова В. Специальное и неспециальное музыкальное содержание. М.: Издательство МГК им. П. И. Чайковского, 2002. 312 с.

9. Холопова В. Формы музыкальных произведений: [Учебное пособие]. СПб.: Лань, 1999. 496 с.

\section{REFERENCES}

1. Kancheli, M. (1970). A large one-part form in the music of the XIX and at the turn of the 20th centuries // Questions of the theory of music. M.: Music, Issue. P. 153-173 [in Russian].

2. Mazel, L. (1979). The structure of musical works. - Moscow: Music [in Russian].

3. Mazel, L., Zukkerman, V. (1967). Analysis of musical works. Elements of music and methods of analysis of small forms. M.: Music [in Russian].

4. Nazaikinsky, E. (1982). Logic of musical composition. Moscow: Music [in Russian].

5. Tyshko, S. (1993). The problem of national style in the Russian opera. Glinka, Mussorgsky, Rimsky-Korsakov. K.: Kiev State Conservatory named after P. Tchaikovsky [in Russian]. 
6. Kholopova, V. (1990). Music as a form of art. M.: Scientific and Creative Center «Conservatory» [in Russian].

7. Kholopova, V. (1983). Musical themes: [Scientific and methodological essay. M. [in Russian].

8. Kholopova, V. (2002). Special and non-special musical content. Moscow: Izdatelstvo MGK im. P. I. Tchaikovsky [in Russian].

9. Kholopova, V. (1999). Forms of musical works: [Textbook]. St. Petersburg: Lan [in Russian].

Стаття надійшла до редакції 22.06.2016

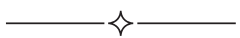

УДК 781.65

Чжу Веньфен, ассистент-стажер кафедры сольного пения

Одесской национальной музыкальной академии им. А. В. Неждановой

\section{АКТУАЛЬНЫЕ МУЗЫКОВЕДЧЕСКИЕ ПОДХОДЫ К ЯВЛЕНИЮ МУЗЫКАЛЬНОЙ РИТОРИКИ}

Целью данной статьи является осуществление анализа сущности риторики как многогранного феномена и выявление специфики ее развития на разных историко-культурных этапах, а также исследование модификации взглядов на музыкальную риторику. Методология работы опирается на историко-библиографический метод, привлекаются системный, компаративный и аналитический подходы. Научная новизна работы заключается в расширении представлений о музыкальной риторике как о семиотико-культурологической области научных интересов музыковедения; в изучении логики и причин изменений научного знания по отношению $\kappa$ музыкальной риторике; в попытке обобщений наиболее актуальных разработок проблем музыкальной риторики. Выводы. Устанавливается широта грании, музыкальной риторики, многообразие подходов к этому феномену, многоаспектность его восприятия и научно-исследовательской оценки, также указывается на невыстроенность, несогласованность основных позиций музыкальной риторики. Обращается внимание на то, что исследование музыкальной риторики с точки зрения теории языка и музыкально-речевой деятельности, то есть с семиотической позиции, в современный период приобретает характер устойчивой $и$ постоянно развивающейся тенденции. Актуализируется понимание музыкальной риторики как выстраивающей определенную семиотическую модель музыки, в которой за основу принимается особая образно-смыс-

(C) Чжу Веньфен, 2016 